\title{
Sustainability Assessment of Goat and Sheep Farms: A Comparison between European Countries
}

\author{
Christina Paraskevopoulou ${ }^{1}$, Alexandros Theodoridis ${ }^{2}{ }^{(0}$, Marion Johnson ${ }^{3}$, \\ Athanasios Ragkos ${ }^{4}$, Lisa Arguile ${ }^{3}$, Laurence Smith ${ }^{5}{ }^{(0)}$, Dimitrios Vlachos ${ }^{1}$ (i) \\ and Georgios Arsenos $6, *$ (D) \\ 1 Laboratory of Statistics and Quantitative Analysis Methods, Logistics and Supply Chain Management, \\ Department of Mechanical Engineering, Aristotle University of Thessaloniki, 54124 Thessaloniki, \\ Greece; chripara@auth.gr (C.P.); vlachos1@auth.gr (D.V.) \\ 2 Laboratory of Animal Production Economics, School of Veterinary Medicine, \\ Aristotle University of Thessaloniki, 54124 Thessaloniki, Greece; alextheod@vet.auth.gr \\ 3 Organic Research Centre, Trent Lodge, Stroud Road, Cirencester GL7 6JN, UK; \\ marion.j@organicresearchcentre.com (M.J.); lisa.a@organicresearchcentre.com (L.A.) \\ 4 Agricultural Economics Research Institute, Hellenic Agriculture Organization "Demeter", 11528 Athens, \\ Greece; ragkos@agreri.gr \\ 5 School of Agriculture, Food and Environment, Royal Agricultural University, Cirencester GL7 6JS, UK; \\ laurence.smith@rau.ac.uk \\ 6 Laboratory of Animal Husbandry, School of Veterinary Medicine, Aristotle University of Thessaloniki, \\ 54124 Thessaloniki, Greece \\ * Correspondence: arsenosg@vet.auth.gr; Tel.: +30-2310-999-988
}

Received: 27 February 2020; Accepted: 10 April 2020; Published: 12 April 2020

check for updates

\begin{abstract}
European sheep and goat farming faces diverse challenges at global or local scales and constitutes an important sector for many countries, playing important sociocultural, economic and environmental roles. A closer examination of the overall sustainability of the sector is necessary to assess the performance of different farm types in various geographical settings. This comparative study evaluates the use of a common sustainability assessment (SA) tool for the major European countries in the sheep and goat sector. In particular, the study reports the results of a SA using the Public Goods (PG) Tool, adapted within the Innovation for Sustainable Sheep and Goat Production in Europe (iSAGE) Horizon 2020 project, which includes questions accounting for 13 dimensions of a sheep and goat farm sustainability. In total, 206 farmers from Greece, Italy, Spain, Finland, United Kingdom, France and Turkey were interviewed, all of which were typical of specific types of a pan-European sheep and goat farm typologies elaborated within iSAGE. The study resulted in composite indicators of performance in each dimension for each country. Finland, Italy and the United Kingdom performed better than other countries, while Turkey and Greece performed below average in most categories. The results highlight challenges for each country but also at the European level, the latter mainly relating to generational renewal and an unwillingness to invest in the adoption of a more sustainable approach with long-term results.
\end{abstract}

Keywords: small ruminants; sustainability; sustainability assessment; goat production; sheep production; dairy; meat

\section{Introduction}

The 1989 United Nations (UN) report "Our common future" raised global awareness of the environmental issues and the future consequences of overuse of natural resources and emphasized the importance of taking action. This led to the further development of the concept of Sustainability 
and "Sustainable Development" (SD) [1]. The authors defined SD as meeting the needs of the present without compromising the ability of future generations to meet their needs. Over time, the notion of SD was expanded to include environmental, social and economic sustainability, as the balance of the three ensures the sustainability of a product, company, supply chain or sector. Later, governance was added as a distinct pillar of sustainability by Food and Agriculture Organization (FAO) of the UN [2] as without oversight the other pillars of sustainability may not always be maintained. In 2015 the UN illustrated sustainability as the common achievement of 17 sustainability goals [3].

By the year 2050, according to the UN estimations, the Earth's population will have grown by $26 \%$, reaching 9.7 billion people [4]. To face this challenge, ensuring food safety and security without compromising the main pillars of sustainability constitutes one of the UN's main goals for sustainable development [5]. Agriculture, including livestock farming, can benefit significantly from sustainable management, as livestock products are of significance both for human consumption, reaching an annual growth of $1.2 \%, 0.4 \%$ and $1.5 \%$ for meat, milk and eggs, respectively [6], but also as source of income especially for vulnerable populations living in the countryside.

Sustainability issues are of particular importance for the sheep and goat sector in Europe, where 16.8 and 130.8 million goats and sheep respectively are reared, ensuring livelihoods for vulnerable populations in rural areas, including those in marginal zones. The shift towards intensification in small ruminant production, where traditional husbandry practices like pastoralism have decreased due to low productivity and prices [7], signals the need for sustainable livestock management in order to ensure the overall viability of the sector $[8,9]$. The threat to the resilience of the sector might further be averted by taking advantage of the opportunities in sustainable production, such as special "lifestyle" market niches, which are flourishing [10]. Therefore, a closer examination of the overall sustainability of the sheep and goat sector in Europe is necessary to assess how different countries, economies and ecosystems perform with regard to the various attributes of sustainability.

Although there have been studies that assess the sustainability in small ruminant farms in France and Spain [8,11-14] and one rapid assessment in organic and low-input farming of 102 dairy cow and goat farms in 9 European Union (EU) countries for the Sustainable Organic and Low Input Dairying (SOLID) project [15], there has not been a larger-scale Sustainability Assessment (SA), with a holistic approach, to evaluate the current condition of European small ruminant farming. Many different frameworks and tools exist for SA with different approaches, as SA is a complex type of appraisal methodology due to its multidisciplinary aspects and system-specific characteristics, i.e., the values, the culture, the target group [16,17]. In order to choose the right approach for a SA, in 2006 Ness, Urbel-Piirsalu, Anderberg and Olsson [18] categorized SA tools according to (a) their temporal characteristics, (b) focus of the tool and (c) the integration of nature-society systems. Arranged according to a time continuum, the result was three general categories and a complementary one: (i) indicators and indices, which are further broken down into non-integrated and integrated; (ii) product-related assessment tools with the focus on Life Cycle Assessment (LCA) where costing and material and/or energy flows of a product or service from a life cycle perspective are assessed; (iii) integrated assessment, looking into policy and strategy integration and (iv) monetary evaluation, a supplementary category when "non-market values" need to be provided for the three main ones.

The most notable SA tools are the pressure-state-response (PSR) framework, the Driving Force Pressure State Impact Response (DPSIR) model, which has been adopted by the European Environmental Agency (EEA) and European Statistical Office, the hierarchical structure of the global reporting initiative (GRI) framework, The United Nations Commission for Sustainable Development (UNCSD) Theme Indicator Framework and the Institute of Chemical Engineers (IChemE) Sustainability Metrics [19]. With respect to farming systems there are a number of proposed methodologies the most notable among them being the Framework for the Evaluation of Sustainable Land Management (FESLM), Indicator of Sustainable Agricultural Practice (ISAP), Multiscale Methodological Framework (MMF), Response-Inducing Sustainability Evaluation (RISE), Sustainability Assessment of the Farming and the Environment (SAFE) and the Sustainability Solution Space for Decision Making (SSP) [20]. 
In order to provide a cohesive SA, after reviewing different frameworks, tools and procedures in 2014, FAO developed the Sustainability Assessment of Food and Agriculture (SAFA) guidelines providing a holistic framework, procedures and protocol [2] aimed at food and agricultural enterprises worldwide.

The purpose of this comparative study is to demonstrate the feasibility of the use of a simple sustainability assessment tool in a uniform way across European countries. A multivariable assessment system based on the Public Goods (PG) Tool, derived from the SAFA guidelines and developed by the Organic Research Centre (ORC), was adapted by the Innovation for Sustainable Sheep and Goat Production in Europe (iSAGE) project (www.isage.eu) and used for this purpose. The study compares farms from seven European countries, which represent different climate zones, and from nine different pan-European typologies categorized by iSAGE. The results of the SA are presented by country in order to facilitate a discussion regarding the effectiveness of the PG Tool in pinpointing the key features and differences across countries as well as to identify and highlight findings for future targeted research.

\section{Materials and Methods}

\subsection{Sustainability Assessment}

Within the iSAGE project an integrated SA was carried out, with the key objective of examining the feasibility of a common assessment framework for the overall sustainability of the main sheep and goat farm types across six European countries and Turkey. In order to choose the best SA tool and indicators for this purpose, the iSAGE project identified and mapped out 21 tools and reviewed them after prioritizing them according to the SAFA guidelines [21,22]. To further secure the applicability and value of SA tools, industry partners were surveyed as to the appropriateness of and their experience with these tools and indicators. It was concluded that the PG Tool, adjusted to the project's goal to increase sustainability in small ruminant farms, was the best option. The tool originally consisted of 11 sustainability themes, defined as "spurs" as this is how the results are visualized: (1) soil management, (2) biodiversity, (3) landscape and heritage, (4) water management, (5) manure management and nutrients, (6) energy and carbon, (7) food security, (8) agricultural systems diversity, (9) social capital, (10) farm business resilience and (11) animal health and welfare [23]. For the needs of iSAGE, the animal health and welfare spur was separated into two; biodiversity was renamed agri-environmental management, and manure and nutrients became fertilizer management. The Governance spur was added to recognize the importance of this pillar of sustainability as described in the SAFA Guidelines [2]. The adapted iSAGE PG Tool has a total of 13 spurs or sustainability themes contributing to the assessment.

\subsection{Elaboration of the PG Tool}

In order to choose the appropriate indicators, iSAGE project partners discussed sustainability issues taking into account the results of a survey of industry partners' opinions and requirements. Through this process, additional indicators relevant to specific types of sheep and goat farms were identified. All these indicators were separated into 3 main categories: animal health, welfare and livestock management indicators, socioeconomic indicators and environmental indicators [22,23].

For the selection of the indicators for the iSAGE PG Tool, the particularities of sheep and goat farming systems, as well as the farms' goals and typology had to be considered [22]. Regarding the animal health, welfare and livestock management indicators, apart from the literature review and the stakeholders survey, previous projects and applications of the PG Tool and government and European Union recommendations were factored in the selection, e.g., the European Food Safety Authority (EFSA) 2014 recommendations [22,23]. The socioeconomic indicators consist of the economic and social aspect. For the former, the economic efficiency of the farms was calculated through the "gross-margin" approach, while product quality and certification, locality, business resilience and long-term profitability were also included $[22,23]$. The social aspect included the on-farm working conditions and the interaction with the social environment $[22,23]$. The environmental indicators 
selection covered a variety of areas based on the SAFA guidelines [2], i.e., atmosphere, water, land, biodiversity and materials and energy as well as from government and industry guidelines and best codes of practice [22,23]. Thus, the newly identified indicators were incorporated in the PG Tool and its different spurs, while the existing indicators were adjusted to the project's goals when needed.

In the adapted version of the PG Tool, each sustainability theme or spur comprises several related subthemes, for example, landscape and heritage has the subthemes (1) historic features, (2) landscape features, (3) management of boundaries and (4) genetic heritage. Under each subtheme the farmer answers a series of questions representing the different indicators. To determine the final score, a rounded average score of the questions in each subtheme is calculated. Using non weighted averages, the subtheme scores generate the overall spur score. The final score of each farm is expressed in an ordinal scale from 1 to 5,1 representing low performance and 5 maximum performance [21,22]. A full description of the calculations, benchmarks used and development of the PG Tool is given in the Organic Conversion Information Service (OCIS) Public Goods Tool Development Report [23].

\subsection{Geographical Scope of the Study and Choice of Farms}

A purposive sample of 206 farms in 6 European countries-Finland (FN), France (FR), Greece (GR), Italy (IT), Spain (ES), and United Kingdom (UK) which represent more than $74 \%$ and $87 \%$ of the European sheep and goat populations respectively-and in Turkey (TR) was used for the analysis as shown in Figure 1. These farms were chosen by local experts participating in the iSAGE project accounting for typical farm sizes of the prevailing farm types in each country and ensuring that farms typical of each previously identified typology were assessed. This choice was based on a pan-European typology which was developed by iSAGE [24]. In this typology, European and Turkish farms were categorized based on their key characteristics including the main species reared (sheep or goat) as well as grazing and feed practices (intensive, semi-intensive, extensive or semi-extensive) and product -dairy, meat or dual-purpose (dual purpose being defined as when the farmer values two or more different products as being of equal importance for farm profitability) [25] (Table 1). The method of choice of farms for the SA does not permit robust statistical comparisons across countries and farm types, but rather yields rich information regarding the prevailing challenges that farms of each type face in each country with respect to their overall sustainability performance. The chosen farms were spread throughout the countries, in different regions and climatic zones as shown in Table 2.

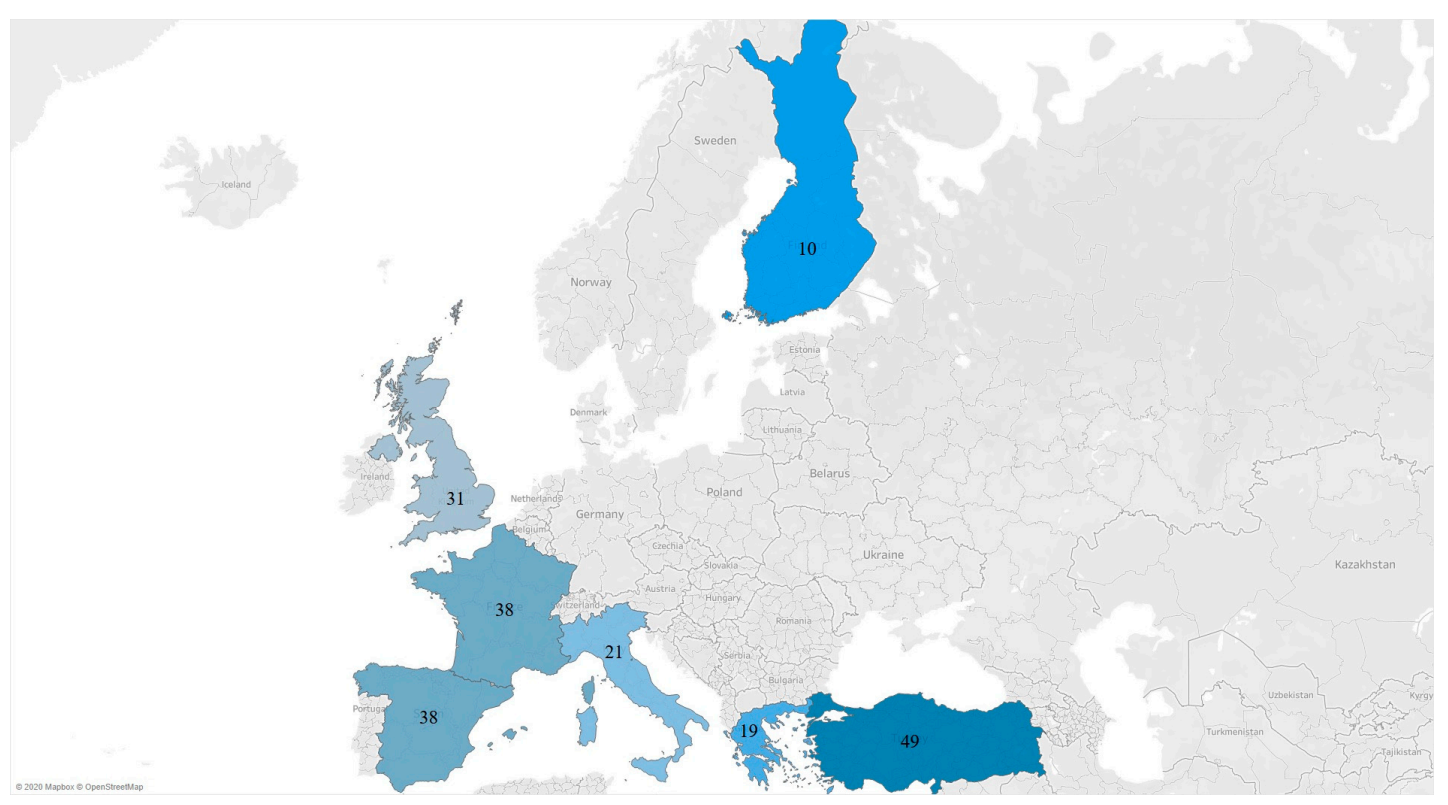

Figure 1. Map of the studied farms (created using Tableau Desktop Professional Edition 2019.4.2 software (Tableau Software, Seattle, DC, USA)). 
Table 1. Number of farms for each farm typology by country.

\begin{tabular}{|c|c|c|c|c|c|c|c|c|}
\hline \multirow{2}{*}{ Farm Typology by Main Species Reared, Practices and Product } & \multicolumn{7}{|c|}{ Country } & \multirow{2}{*}{ Total } \\
\hline & ES & FN & FR & GR & IT & TR & UK & \\
\hline Goat: Dual-purpose farms (e.g., meat and wool, meat and dairy) & 0 & 0 & 0 & 2 & 1 & 7 & 0 & 10 \\
\hline $\begin{array}{l}\text { Goat: Intensive dairy farms (e.g., high input of } \\
\text { purchased feedstuff) }\end{array}$ & 9 & 0 & 6 & 3 & 1 & 3 & 4 & 26 \\
\hline Goat: Intensive meat farms & 0 & 0 & 0 & 0 & 1 & 0 & 2 & 3 \\
\hline $\begin{array}{l}\text { Goat: Semi-intensive or extensive dairy farms (e.g., normally } \\
\text { pasture fed animals) }\end{array}$ & 7 & 0 & 5 & 2 & 7 & 7 & 0 & 28 \\
\hline Goat: Semi-intensive or extensive meat farms & 4 & 0 & 0 & 0 & 0 & 3 & 1 & 8 \\
\hline Sheep: Dual-purpose farms & 2 & 5 & 0 & 4 & 4 & 9 & 2 & 26 \\
\hline Sheep: Intensive dairy farms & 4 & 0 & 0 & 4 & 0 & 3 & 1 & 12 \\
\hline Sheep: Intensive meat farms & 0 & 1 & 4 & 0 & 0 & 9 & 3 & 17 \\
\hline Sheep: Semi-intensive or extensive dairy farms & 2 & 0 & 14 & 3 & 4 & 0 & 2 & 25 \\
\hline Sheep: Semi-intensive or extensive meat farms & 10 & 4 & 9 & 0 & 3 & 8 & 16 & 50 \\
\hline Other & 0 & 0 & 0 & 1 & 0 & 0 & 0 & 1 \\
\hline
\end{tabular}

The characteristics of the farms are presented in Tables 2 and 3. Most farms were located in the Mediterranean/southern climate areas and at $>300 \mathrm{~m}$ above sea level (Table 2). Medium quality soils prevailed on most farms. About two out of three farms had more than $50 \%$ of their land in a less favored area, meaning that they were facing natural constraints relating to altitude, climate and steepness of land, which were limiting their productivity. Most of the farms were managed conventionally but there were several farms producing Protected Designation of Origin (PDO), Protected Geographical Indication (PGI) or Traditional Specialties Guaranteed (TSG) products. As shown in Table 3, the size of the farms, flock sizes and the number of employees varied across countries as well as within the countries under study, while the ratios of the total revenue from sheep and goats without subsidy indicate that there are variations in how the farms produce and perform.

Table 2. Farm categorical characteristics counts by country.

\begin{tabular}{|c|c|c|c|c|c|c|c|c|c|}
\hline & & \multicolumn{7}{|c|}{ Country } & \multirow{2}{*}{ Total } \\
\hline & & ES & FN & FR & GR & IT & TR & UK & \\
\hline \multirow{4}{*}{ Climate Area } & Alpine & 0 & 0 & 0 & 0 & 14 & 0 & 0 & 14 \\
\hline & Atlantic & 0 & 0 & 20 & 0 & 0 & 0 & 31 & 51 \\
\hline & Northern & 0 & 10 & 0 & 0 & 0 & 0 & 0 & 10 \\
\hline & Southern & 38 & 0 & 18 & 19 & 7 & 49 & 0 & 131 \\
\hline \multirow{4}{*}{ Region } & East & 15 & 0 & 0 & 3 & 1 & 24 & 6 & 49 \\
\hline & North & 2 & 2 & 0 & 14 & 14 & 0 & 3 & 35 \\
\hline & South & 16 & 2 & 24 & 0 & 3 & 24 & 11 & 80 \\
\hline & West & 5 & 6 & 14 & 2 & 3 & 1 & 11 & 42 \\
\hline \multirow{5}{*}{ Dominant soil type } & Chalk and limestone soil & 9 & 0 & 6 & 0 & 5 & 4 & 5 & 29 \\
\hline & Heavy soil & 16 & 1 & 5 & 5 & 7 & 6 & 7 & 47 \\
\hline & Medium soil & 5 & 2 & 17 & 13 & 8 & 27 & 10 & 82 \\
\hline & Peaty soil & 1 & 1 & 0 & 0 & 0 & 1 & 2 & 5 \\
\hline & Sandy and light soil & 7 & 6 & 10 & 1 & 1 & 11 & 7 & 43 \\
\hline \multirow{3}{*}{$\begin{array}{c}\text { Organic/low } \\
\text { input/conventional }\end{array}$} & Conventional & 21 & 4 & 30 & 15 & 1 & 44 & 18 & 133 \\
\hline & Low input & 13 & 0 & 3 & 2 & 3 & 4 & 10 & 35 \\
\hline & Organic & 4 & 6 & 5 & 2 & 17 & 1 & 3 & 38 \\
\hline \multirow{6}{*}{$\begin{array}{l}\text { Does the farm produce PDO, } \\
\text { PGS or TSG products? }\end{array}$} & N/A & 0 & 3 & 0 & 0 & 0 & 9 & 0 & 12 \\
\hline & No & 24 & 6 & 14 & 14 & 21 & 39 & 27 & 145 \\
\hline & Yes & 0 & 0 & 0 & 5 & 0 & 0 & 0 & 5 \\
\hline & Yes-PDO & 11 & 0 & 14 & 0 & 0 & 0 & 3 & 28 \\
\hline & Yes-PGS & 3 & 0 & 10 & 0 & 0 & 0 & 1 & 14 \\
\hline & Yes-TSG & 0 & 1 & 0 & 0 & 0 & 1 & 0 & 2 \\
\hline
\end{tabular}


Table 2. Cont.

\begin{tabular}{|c|c|c|c|c|c|c|c|c|c|}
\hline & & \multicolumn{7}{|c|}{ Country } & \multirow{2}{*}{ Total } \\
\hline & & ES & FN & FR & GR & IT & TR & UK & \\
\hline \multirow{2}{*}{$\begin{array}{l}\text { Is more than } 50 \% \text { land in a less } \\
\text { favored area? }\end{array}$} & No & 7 & 0 & 8 & 10 & 4 & 7 & 27 & 63 \\
\hline & Yes & 31 & 10 & 30 & 9 & 17 & 42 & 4 & 143 \\
\hline \multirow{2}{*}{$\begin{array}{l}\text { Do you operate a landless } \\
\text { livestock production system? }\end{array}$} & No & 29 & 10 & 38 & 19 & 21 & 41 & 31 & 189 \\
\hline & Yes & 9 & 0 & 0 & 0 & 0 & 8 & 0 & 17 \\
\hline \multirow{6}{*}{$\begin{array}{l}\text { What is the level of } \\
\text { agri-environmental } \\
\text { participation? }\end{array}$} & $\begin{array}{l}\text { Basic/low level involvement, } \\
\text { with some financial compensation }\end{array}$ & 6 & 2 & 13 & 5 & 1 & 17 & 6 & 50 \\
\hline & Cross compliance & 0 & 0 & 0 & 8 & 0 & 0 & 0 & 8 \\
\hline & Higher level scheme & 0 & 0 & 0 & 0 & 2 & 0 & 0 & 2 \\
\hline & $\begin{array}{l}\text { Just enough to qualify for single } \\
\text { farm payment }\end{array}$ & 22 & 0 & 17 & 3 & 2 & 6 & 6 & 56 \\
\hline & $\begin{array}{l}\text { More demanding, higher level } \\
\text { involvement, with greater } \\
\text { financial compensation }\end{array}$ & 8 & 8 & 7 & 1 & 14 & 4 & 9 & 51 \\
\hline & None & 2 & 0 & 1 & 2 & 2 & 22 & 10 & 39 \\
\hline
\end{tabular}

Table 3. Numerical characteristics of the farms used in the study (mean \pm standard deviation) by country.

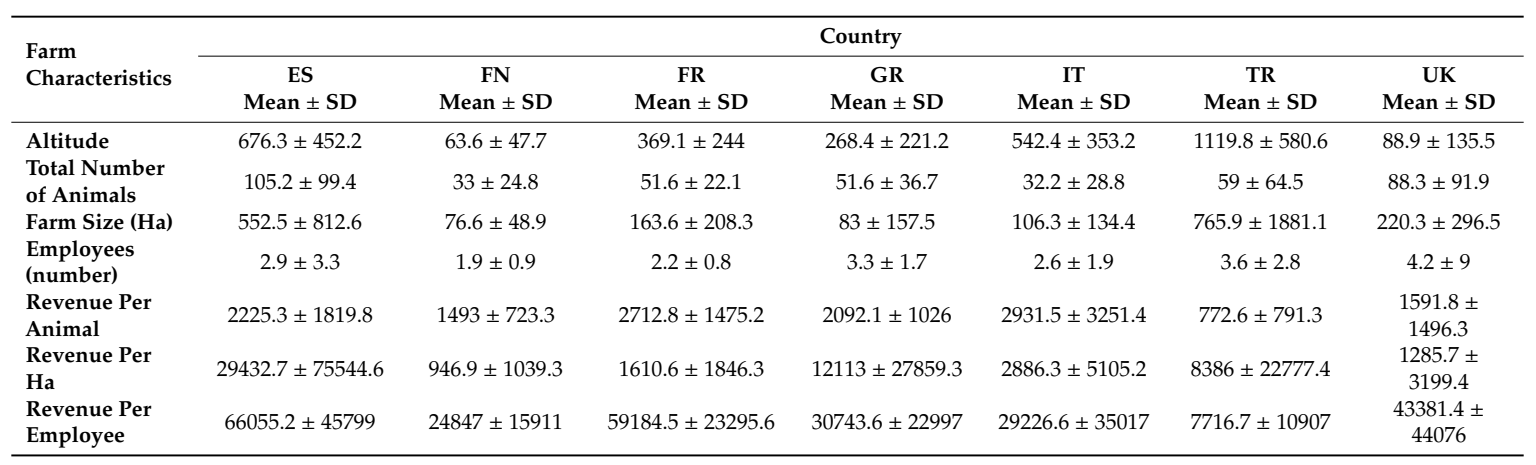

SD: Standard Deviation.

The farms included in this initial study are only a small snapshot of the number of sheep and goat farms in each country and reflect farmers who were open to the idea of assessing their sustainable practices as part of a research project.

\subsection{Data Collection and Interpretation}

Data were collected through on-farm surveys from 2015 to 2018. Enumerators visited the farms and conducted the assessment through a semi-structured questionnaire, with closed and open-ended questions based on the iSAGE PG Tool indicators. Each interview required on average 4 hours of the farmers' time. The assessment began with an introductory section about the farm, followed by a discussion of fuel use exploring the farms use of energy for each enterprise with the information contributing to the Energy and Carbon theme, then progressed to questions about each of 13 the sustainability themes/spurs. In total, whilst undertaking the SA, the farmer answers 154 questions (Appendix A). It should be noted that responses to separate questions in the sustainability themes are at times combined with the initial information in order to provide the final score of each question for each farm. For example, within the spur 'social capital', the number of staff employed FTE is incorporated with total utilized agricultural area for comparison with benchmark data when calculating the overall score.

The average farm scores were then aggregated and averaged in order to calculate the average sustainability theme "spur" score per country. The average performance of each country for each spur was visualized using boxplots generated with SPSS $25{ }^{\circledR}$ software (SPSS Inc., Chicago, IL, USA). A line representing the average score in each spur was drawn in order to illustrate country-specific differences from the "global" average of all sampled farms. 


\section{Results}

\subsection{Soil Management Score}

It draws on the subthemes: (1) soil analysis, (2) soil management, (3) grazing and (4) erosion.

As shown in Figure 2a, Finnish farms achieve the highest average score in terms of sustainable soil management, while Italian, French and UK farms also perform well. Spanish and Turkish farms exhibit the highest variance, which can be explained by the number of farms and the different farm types studied, while it also reflects a potentially lower perception of the importance of soil management to livestock farmers.

\subsection{Agri-Environmental Management Score}

It draws on the subthemes: (1) Agri-environmental participation, (2) rare species, (3) conservation plan, (4) habitats and (5) herbicide and pesticide use.

As shown in Figure 2b, farms appear to achieve lower scores in the "Agri-environmental Management" spur than in soil management. This depicts a likely lower focus of farmers on the importance of environmental decision-making, ranging from conservation and management of natural habitats to rational use of pesticides. Lower performance can partially be explained by possible low scores on indicators concerning the number of rare breeds and habitats within the farm (i.e., small percentage of permanent pastures and native woodland and lack of wildlife habitats) as not all farms will be able to embrace these indicators in the short term. Greece appears to perform least well in this category with an average score of 1.84, followed by Turkey (2.19), while United Kingdom and Finland appear to be the leaders of the category.

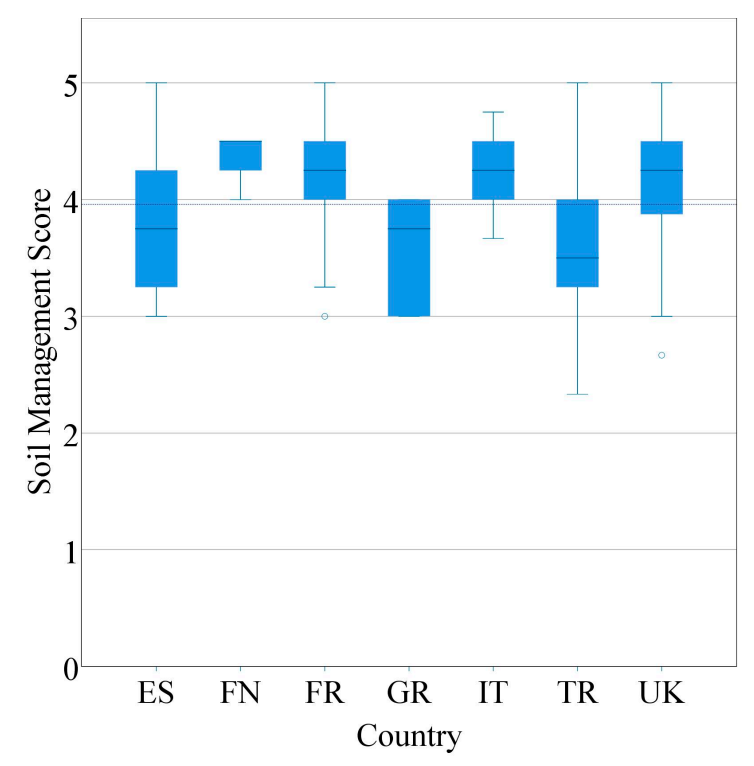

(a)

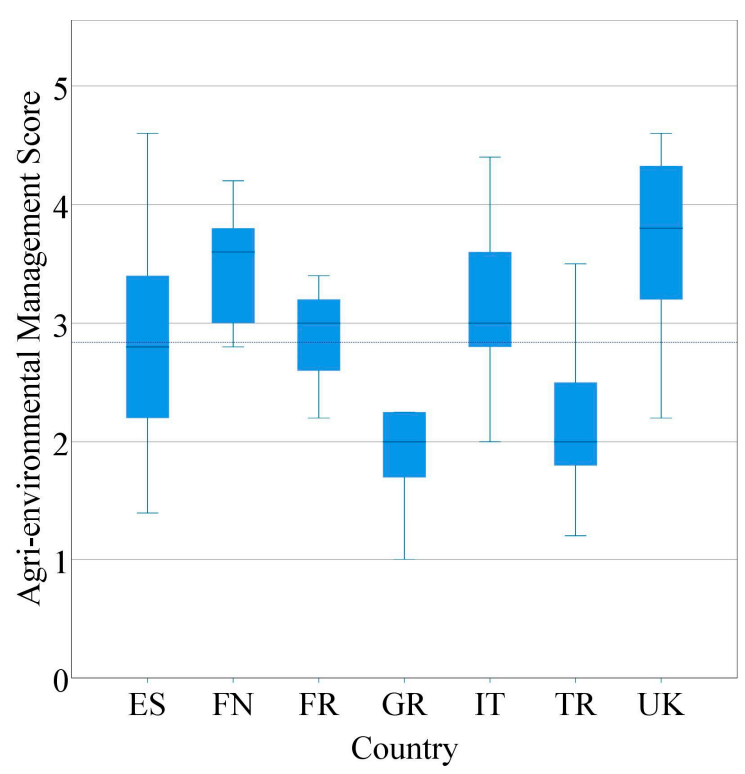

(b)

Figure 2. Boxplots of scores for every studied country: (a) soil management score and (b) agri-environmental management score.

\subsection{Landscape and Heritage Score}

It draws on the subthemes (1) historic features, (2) landscape features, (3) management of boundaries and (4) genetic heritage.

The Landscape and Heritage spur assesses the importance of historical and landscape elements of the farm as well as features of the natural environment. Scores for this spur are also low, as presented in Figure 3a, Spain and Turkey appear to have the largest range of values as well as the largest interquartile 
range. Again, Turkey and Greece achieve the lowest sustainability scores, whereas Finland, Italy and the United Kingdom have the highest. In particular, farms achieve relatively low scores regarding landscape diversity, monuments and traditional buildings.

\subsection{Water Management Score}

It draws on the subthemes: (1) taking steps to reduce pollution/maximize efficiency, (2) flood defenses and runoff prevention, (3) water management plan and (4) irrigation-when there is no irrigation, farmers are positively scored for management practices in this activity.

The Water Management scores are mostly formulated with regards to the existence of a water and irrigation management plan, as no significant variations were observed in other categories-especially regarding flooding and runoff water risks. In this category, Greece ranks lowest, probably as most of the interviewed farmers only utilize water for livestock and are not producing additional feedstuffs on-farm and thus are unlikely to have management plans. Finland leads the category followed by Italy, while Turkey performs above average but with a significant variance as shown in Figure $3 \mathrm{~b}$.

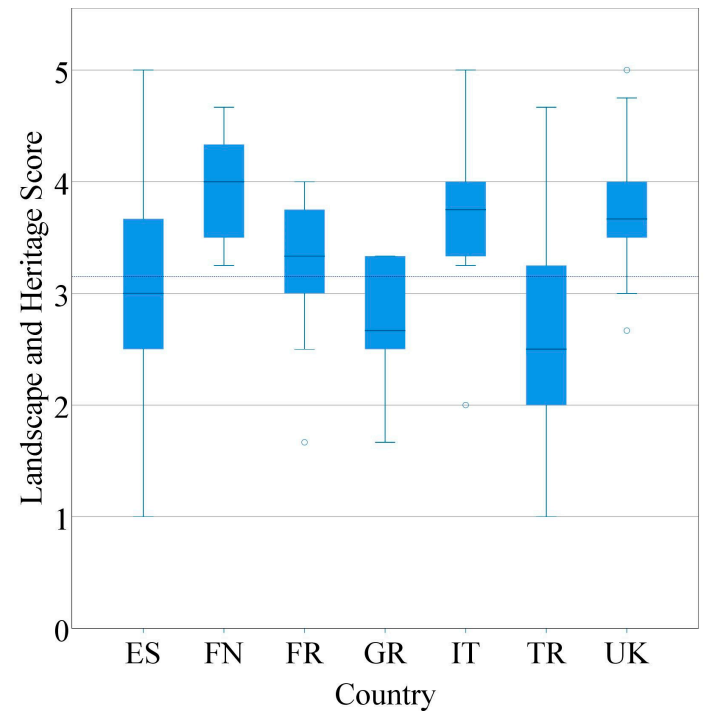

(a)

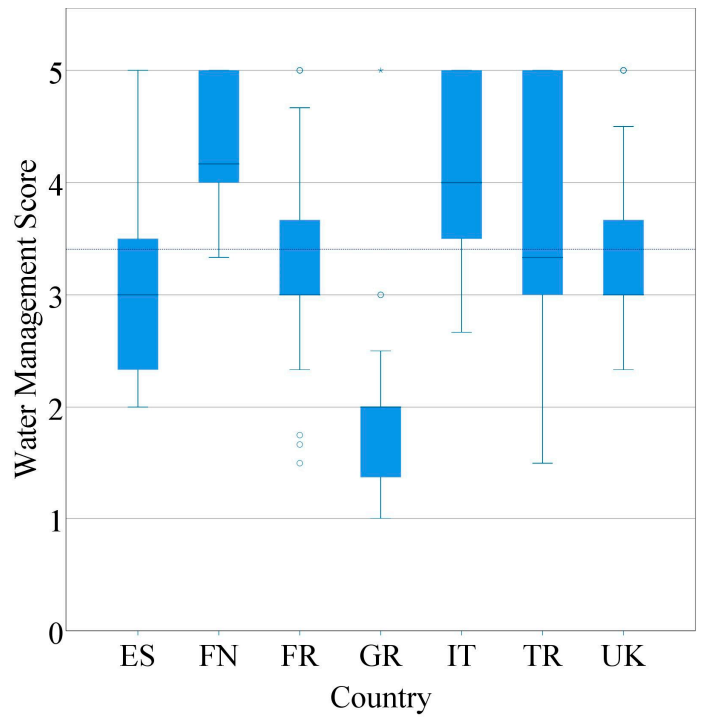

(b)

Figure 3. Boxplots of scores for every studied country: (a) landscape and heritage score and (b) water management score.

\subsection{Fertilizer Management Score}

It draws on the subthemes: (1) nutrient planning, (2) manure management and (3) farm waste disposal.

This category exhibits a pattern similar to that of the previous spur. Greece is the country with the lowest score, while Finland and Italy, followed closely by the United Kingdom, perform considerably better as depicted in Figure 4a. The lack of a waste management and recycling plans seems to be the main reason for lower performance, indicating the low levels of adoption of circular economy principles and methods in the surveyed farms in general.

\subsection{Energy and Carbon Score}

It draws on the subthemes: (1) energy benchmark score, (2) energy saving options, (3) greenhouse gases, (4) land use change and (5) renewables. The energy benchmark score provides a collection of benchmark values based on farm fuel use data provided, for each enterprise on the farm.

Although the climate and green energy are part of UN's 2030 Sustainable Development Agenda, the results of the assessment in the "Energy and Carbon" spur indicate that European small ruminant 
production has potentially not yet incorporated elements of energy conservation or control of greenhouse gases produced on site. Greece and Turkey are rated lower than the other countries, mainly due to the relatively higher use of petrol. Italy has the highest performance for theme. (Figure 4b). Differences in performance in this spur also reflect the different strategies taken by farmers regarding Greenhouse gas (GHG) emission reduction. In addition, the lack of generation and use of renewable energy sources and technologies combined with the lack of an energy monitoring plan and audit seem to be the factors behind low performances in this category.

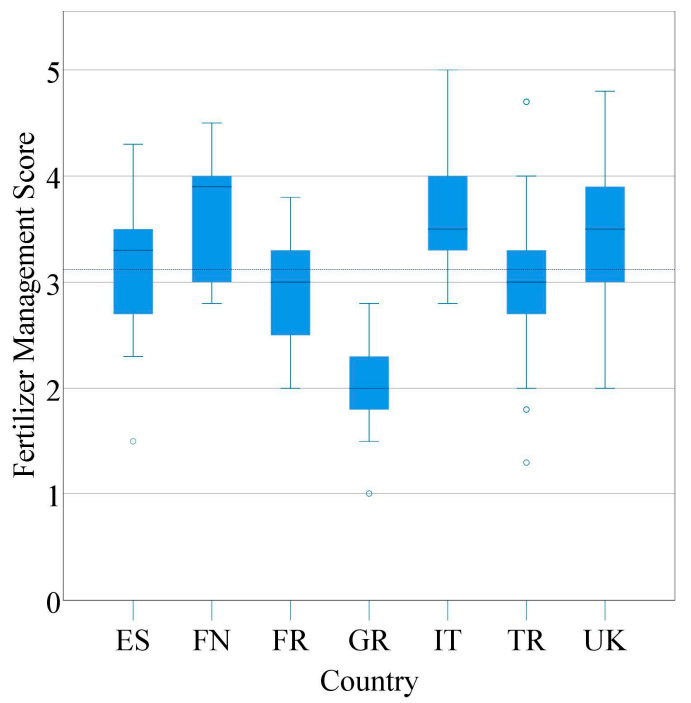

(a)

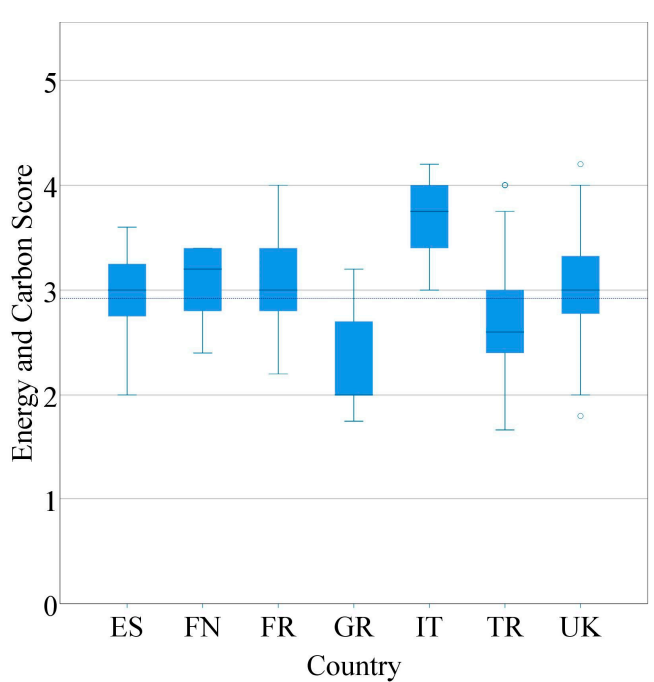

(b)

Figure 4. Boxplots of scores for every studied country: (a) fertilizer management score and (b) energy and carbon score.

\subsection{Food Security Score}

It draws on the subthemes: (1) total productivity, (2) local food, (3) breeds adapted for local conditions, (4) off-farm feed and (5) food quality and traceability.

This category's leader is Italy, while the average score of Greek farms is the lowest (Figure 5a). The differences between the two countries provide an indication of the importance of locally produced livestock products in their agricultural economies-for instance, in Greece there are 21 PDO cheeses compared to 47 in Italy. There is room for improvement in this category for all farms due to a frequent dependency on feed produced off-farm and lack of food quality and traceability certifications.

\subsection{Agricultural Systems Diversity Score}

It draws on the subthemes: (1) cropland diversity, (2) livestock diversity, (3) marketing and (4) on farm processing.

Diversification in sheep and goat supply chain, including low diversity of marketing options, is an important element of socioeconomic sustainability. As demonstrated in Figure 5b, this spur has the lowest average and median score across all categories. Among the participating countries, Italy scores borderline over 3.5. The lack of diversity of the farming system in both the number of species and the number of breeds and restricted choices in marketing outlets are the main causes for poor performance. 


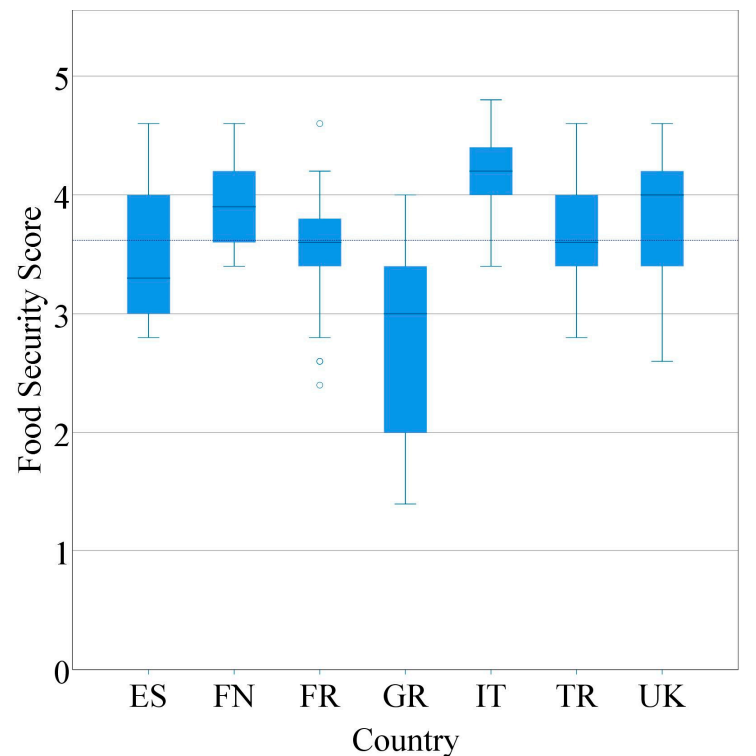

(a)

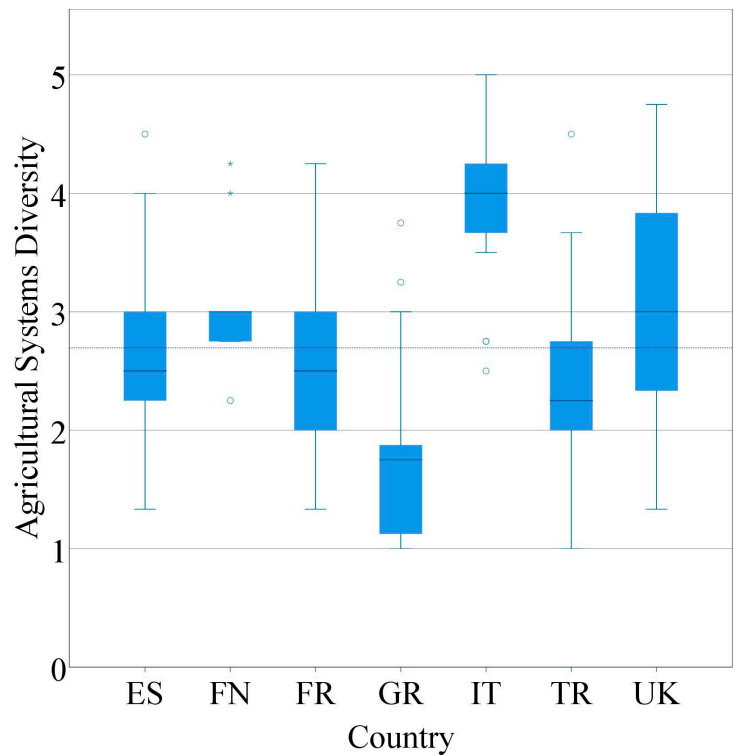

(b)

Figure 5. Boxplots of scores for every studied country: (a) food security score and (b) agricultural system diversity score.

\subsection{Social Capital Score}

It draws on the subthemes (1) employment, (2) skills and knowledge, (3) community engagement, (4) public access and (5) human health.

Regarding social capital, as shown in Figure 6a, Finland and Italy, the latter with large variability, appear to rank highest, while Greece underperforms. The remaining countries performed similarly. The number of employees and a general lack of training programs for farm personnel are the drivers in the employment domain, while the lack of public access to farms and of engagement with the community have an important impact on the results. Low performance in this spur also reflects informal employment arrangements on many of the farms examined.

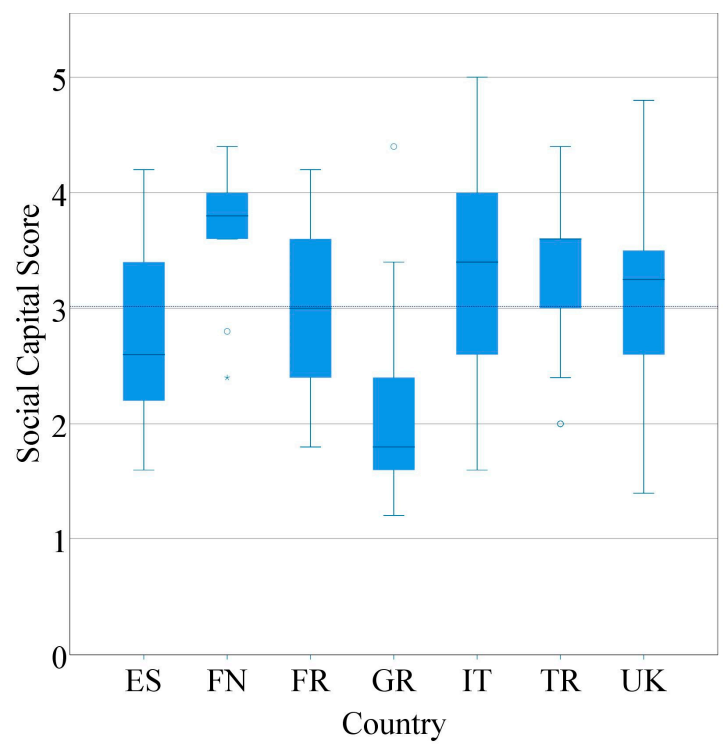

(a)

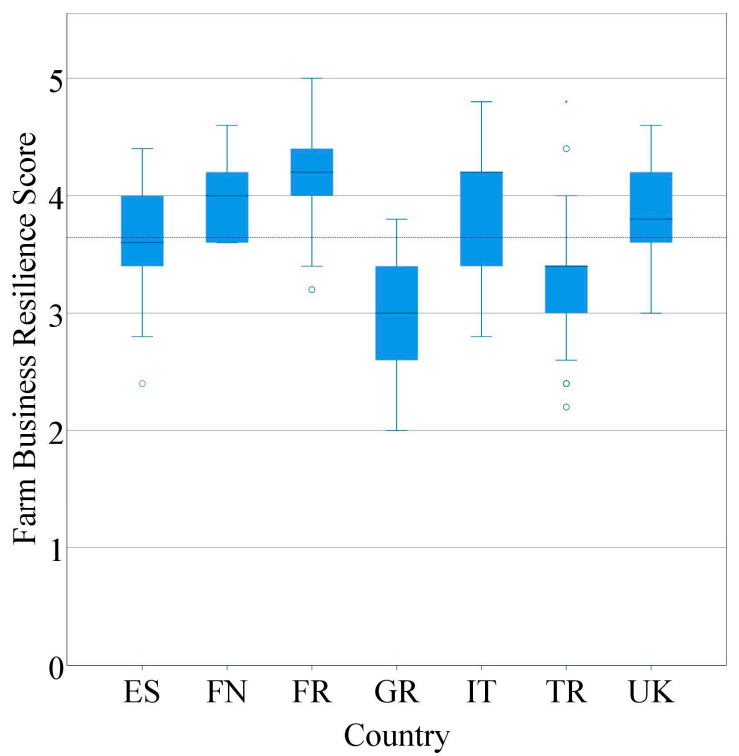

(b)

Figure 6. Boxplots of scores for every studied country: (a) social capital score and (b) farm business resilience score. 


\subsection{Farm Business Resilience Score}

It draws on the subthemes: (1) farm resilience, (2) flexibility, (3) vision/strategy and (4) information searching/networking.

Figure $6 \mathrm{~b}$ depicts how the farm performs as a business and how productive and profitable it is. French and Finnish farms appear to be the most resilient and keep an open communication channel with the sector and the supply chain stakeholders. On the other hand, Greece is the least resilient, partially as a result of the general economic crisis, which also affected the economic performance of farms [24], followed by Turkey, where farms tend not to have many sources of income and have not carried out investments as planned. Overall low performances in this spur demonstrate the lack of entrepreneurial organization of the sheep and goat farms investigated and a relatively low focus on issues relating to strategic management, long-term planning and monitoring of performance.

\subsection{Animal Health Score}

It draws on the subthemes: (1) staff resources, (2) animal health and (3) biosecurity.

As shown on Figure 7a, United Kingdom and Finland lead the Animal Health spur-with Spain and Italy following closely-as they perform in a satisfactory way in all categories. Greece and Turkey, although they perform better than they do in other spurs, appear to be less sustainable in this dimension. This result reflects the tendency of farms in these countries to introduce animals into mating groups at younger ages, while they also lack planning to ensure animal health and biosecurity issues.

\subsection{Animal Welfare Score}

It draws on the subthemes: (1) ability to perform natural behaviors, (2) housing and (3) feeding.

This category depicts the farm's behavior towards its livestock and presents the highest scores among all spurs. United Kingdom is the leader, as shown in Figure $7 \mathrm{~b}$, mainly due to the higher time allocated to animals for grazing and to the better housing conditions for livestock. Although all countries on average perform better than in other spurs, Turkey and Greece are ranked lowest.

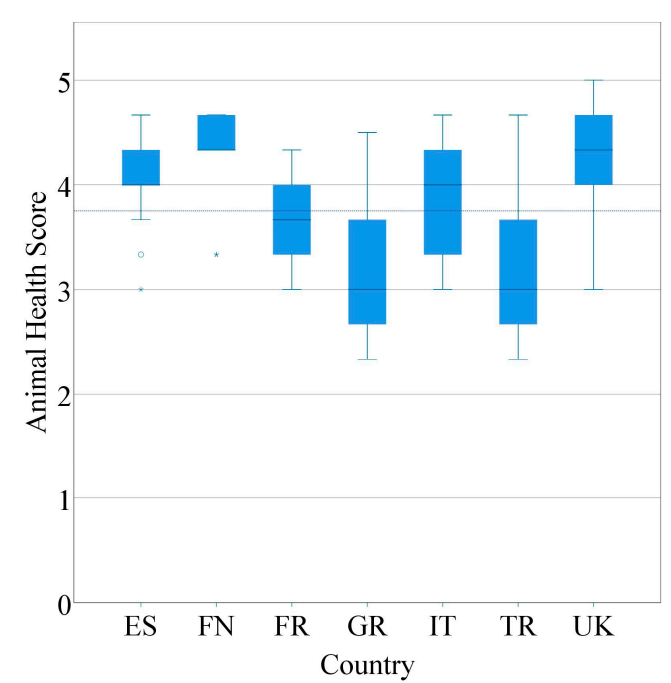

(a)

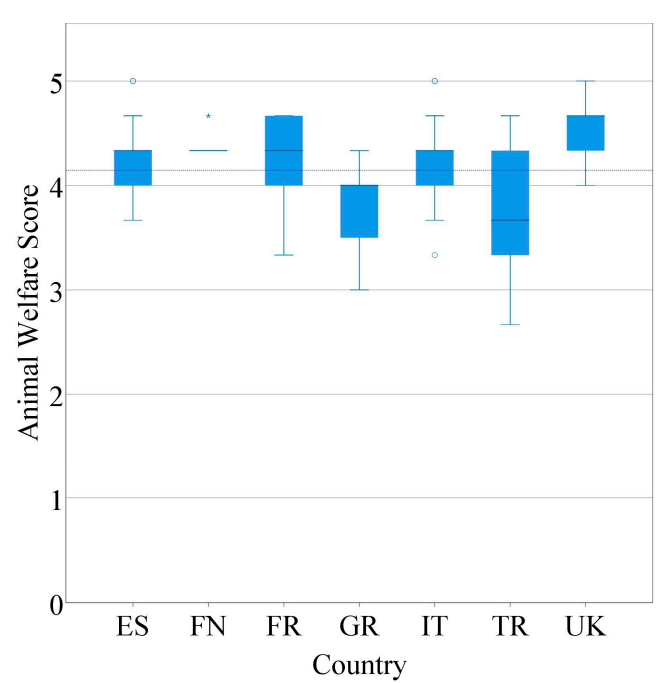

(b)

Figure 7. Boxplots of scores for every studied country: (a) animal health score and (b) animal welfare score.

\subsection{Governance Score}

It draws on the subthemes: (1) ethics, (2) accountability, (3) participation, (4) rule of law and (5) holistic management. 
As shown on Figure 8, Greece and Turkey have very low average scores and a high variability in farm scores in the governance spur. In Greece, low performance is related to the poor connection of farms with stakeholders downstream in the supply chain, resulting in production which sometimes does not match the requirements of the market. For Turkish farms, on the other hand, the lack of cooperation, change and information regarding innovation in farming practices and tools are the main drivers of low scores. Spain achieves the highest score demonstrating a relatively higher level of integration of supply chain stakeholders and participatory governance approaches.

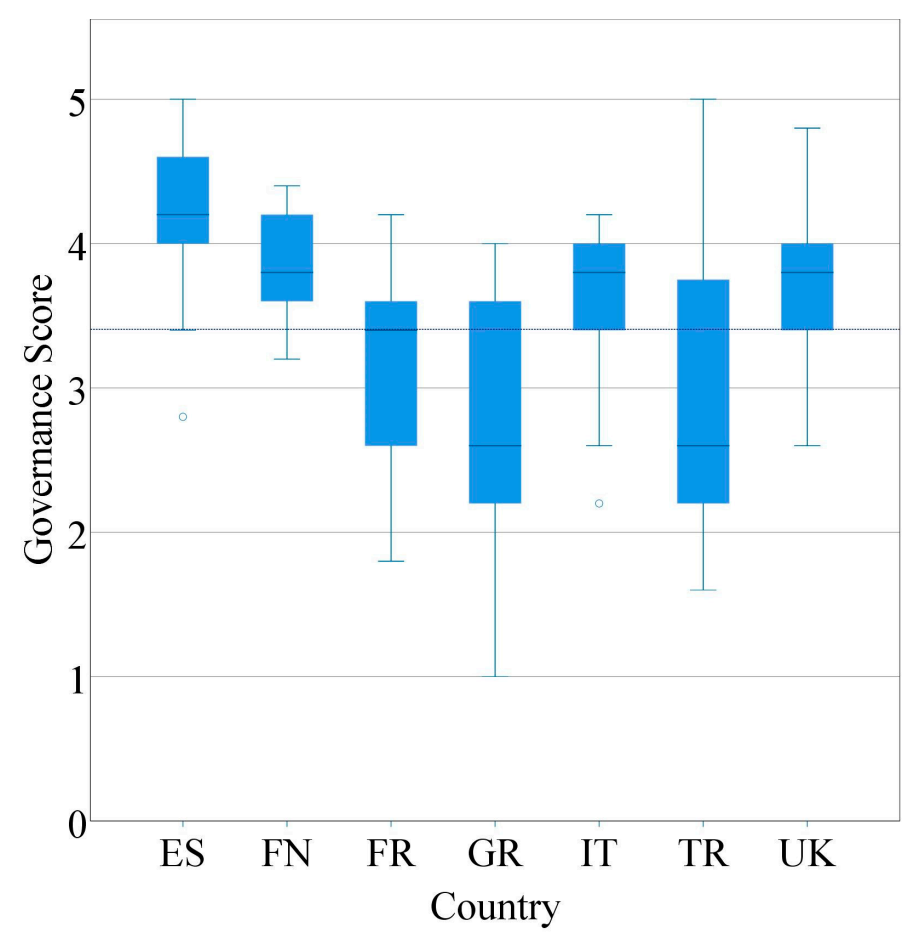

Figure 8. Boxplot of governance score per country.

\section{Discussion}

The results show the sustainability performance in each country, portrayed by theme. Finland appears to be the most sustainable among the seven participating countries, ranking first in 5 out of 13 categories, and being above average in all categories. Water management, soil management and fertilizer management prove that the preservation of the natural capital is a goal for farmers, while the excellent performance in landscape and heritage and the social capital spur prove that the society and the preservation of their lands are important to them.

United Kingdom and Italy perform higher than average in all categories and each one respectively leads three categories. Specifically, UK leads the animal health, animal welfare and agri-environmental management spurs, all relating to higher environmental and welfare standards. Italy, on the other hand, leads the energy and carbon, food security diversity spurs, which are all in-line with the 2030 UN sustainability goals that are vastly important for EU's sustainability agenda. Therefore, Finnish, UK and Italian farms can be regarded as reasonably sustainable.

France and Spain each rank the highest only in farm business resilience and governance spurs respectively. Both economics and governance were identified by SAFA as being important contributors to overall sustainability. At the same time, they both rank, on average, above the mean for each spur, which shows their overall acceptable performance in all dimensions of sustainability.

Turkey underperforms in the sustainability assessment in comparison to the countries mentioned above. Although Turkish farms score higher than average regarding social capital and water management and marginally higher regarding food security; its performance is very low in all 
other categories. Greece achieves the lowest performance in almost all categories and underperforms in the remaining ones. The reason for lower economic performance relates to the country's economic crisis, which burdens farms with higher expenses and lower margins. Greece faces the challenges common to other countries-for instance, the lack of a younger generation entering agriculture [26-28] and of a work force willing to invest time and money in more sustainable patterns of livestock production with a long-term perspective. Nonetheless, although the challenge is common, in Greece it is coupled with persistent structural problems relating to small farm size and a lack of an enabling regulatory framework, impacting the sustainability performance of farms.

In the Horizon 2020 project SOLID, the PG Tool was used to compare 70 organic and 32 low input dairy farms in nine countries across Europe [15]; however, goat farms were only studied in Belgium, Spain and Greece. In both the iSAGE and SOLID studies, the Agricultural System Diversity and Agri-Environmental Management spurs achieved the lowest scores. The PG Tool in the SOLID project included more information on the grasslands and sheep and goat breeds than the iSAGE PG Tool, so the results are not directly comparable. On the other hand, animal health and welfare was the leading spur in both studies, which raises questions regarding the influence of the subjective opinions of respondents on the final results. Comparing the results per country, both studies have Greece performing the lowest on average.

The findings should be considered in the light of some limitations introduced by the SA Tool and the small sample size, in particular, farmers' subjective responses and incomplete information in some cases. However, this study demonstrated some trends regarding the overall sustainability of the European sheep and goat sector that should attract significant scientific attention. In addition, these results highlight priorities to enhance the overall sustainability of sheep and goat production and are thus of equal importance in the formulation of future policy. For both these domains, further and larger scale studies at the European level are needed to provide more detailed and statistically important results as well as more generally applicable measures and interventions.

\section{Conclusions}

Sustainability considerations are at the center of discussions about the future of agriculture globally. The livestock sector in Europe is under scrutiny and is challenged by sustainability issues. The small ruminant sector must adopt sustainable practices and principles in order to become more resilient and competitive. In this study, a sustainability assessment was conducted across sheep and goat farms in six European countries and Turkey. The results revealed that all farm types in all countries are facing challenges regarding their overall sustainability. It would appear from this study that both Greek and Turkish farmers are struggling the most while Finnish, Italian and UK farms seem to be addressing sustainability challenges in a more coherent way, introducing or fostering sustainable production practices and innovations. However, these are indicative results and further research is required in order to have a clear depiction of the sector.

This initial study has provided an averaged indication of the sustainability of the industry in each country. To truly promote a sustainable industry and to provide livelihoods for the regions sheep and goat farmers, further assessments of a much larger number of farms are necessary. In addition, other methods of analyzing the data, e.g., clustering, may be useful to determine the reasons why certain farms underperform as opposed to others. Each spur should be examined in depth and recognition given to the different climatic zones and methods of farming (by typology) in each country. At the same time, social and economic analysis of the sector and recording and evaluation of state level initiatives and incentives for each country may provide useful information as to what improvements can be made in order to achieve the maximum results in regard to sustainability.

Author Contributions: C.P. provided data curation, analysis and visualization and wrote the draft manuscript. A.T. contributed to the analysis, interpretation of the results and literature review. M.J. conceptualized the case study, contributed to the methodology, reviewed and edited the manuscript and validated the results. A.R. contributed to the analysis and interpretation, reviewed and edited the manuscript and validated the results. 
L.A. analyzed the initial data. L.S. developed the PG tool and adapted it for iSAGE. D.V. contributed to the analysis, interpretation and validation of the results. G.A. contributed to the design of the case study, reviewed the manuscript and validated the results. All authors have read and agreed to the published version of the manuscript.

Funding: This study was supported by the European Union's Horizon 2020 Research and Innovation Action (RIA) through the project "Innovation for sustainable sheep and Goat production in Europe (iSAGE)" under grant agreement 679302 .

Acknowledgments: The contribution of farmers that provided data during sustainability assessments is greatly acknowledged.

Conflicts of Interest: The authors declare no conflict of interest.

\section{Appendix A}

Soil Management

Landless livestock production system (i.e., 100\% housed AND all feed produced off-farm)?

1. Soil analysis

- How often do you undertake soil analysis?

- Are you increasing, decreasing or maintaining soil organic matter levels (if no testing is carried out then the "don't know" option should be used here)?

2. Soil management

- What \% of arable land is left as bare ground (e.g., over winter stubble without a cover crop) over the winter?

- $\quad$ On what percentage of your utilized agricultural land are you implementing measures that can improve soil organic matter concentrations (e.g., manure and compost application, use of ley periods in arable rotations)?

3. Grazing

- Is there any soil damage caused by overgrazing?

4. Erosion

- $\quad$ Please report \% of land affected by erosion

Agri-Environmental Management

Do you operate a landless livestock production system (i.e., 100\% housed AND all feed produced off-farm)?

1. Agri-environmental participation

- How many environmental management options do you undertake on your farm?

2. Rare species

- How many rare species do you have evidence of on your farm?

3. Conservation plan

- Have you considered conservation on your farm?

4. Habitat

- What is the amount of land that is permanent pasture? (taken from Initial data collection sheet). 
- What percentage of permanent pasture is managed as "low input" or "very low input" (taken from initial data collection sheet)

- What is the amount of land that consists of native species woodland-broadleaved, mixed or coniferous?

- To what extent do you manage farm woodland? n/a, not at all, manage some woodland edges, manage all woodland edges, woodland management for conservation/biodiversity, very active woodland management for conservation/biodiversity.

- Do you have wildlife habitats (e.g., wet grassland, scrubland, wildflower meadows) or are you restoring and/or establishing wildlife habitats on your land? If so, how much land is a wildlife habitat as a percentage of total land area?

5. Herbicide and other pesticide use

- Do you use herbicides, insecticides, fungicides or other products (e.g., straw shorteners)?

- When using pesticides/other control measures, how do you decide on amounts to use?

- Do you take action to prevent contamination of soil, water courses, lakes and ponds? Consider not just sprays but also granular products such as metaldehyde.

- Do you operate a landless livestock production system (i.e., $100 \%$ housed AND all feed produced off-farm)?

Landscape and Heritage

Landless livestock production system (i.e., 100\% housed AND all feed produced off-farm)?

1. Historic features

- Are there historic features present on the farm (including archaeological features, traditional buildings, listed monuments, traces of ancient agricultural investments such as irrigation canals or terrace crops)? If yes then answer question below.

- If there are, how much maintenance/care do you give them? None, little, some, much, N/A (note: in the case of archaeological features a high level of care may involve keeping them buried and not ploughing/cultivating in the areas where they exist).

2. Landscape features

- Are the farm buildings in keeping with the surrounding area (i.e., using local materials, maintaining the same style of building as is common in the area)?

- Do you feel your farm enhances or detracts from the natural area? Or does it have no impact (the visual impact of the farm in the surrounding landscape has been limited by using greenbelts, by avoiding the use of eye-catching elements and the buildings are in a concentrated, compact area)?

- Is there a good general order and tidiness on the farm? e.g., are items such as bathtubs, old machinery, tyres absent as much as possible?

3. Management of boundaries

- Are you taking action to restore/manage appropriate boundary features (e.g, hedges, hedge banks, earth banks, stone faced banks, stone walls, ditches)?

4. Genetic heriatge

- Do you farm any rare breeds?

Water Management

1. Implementation of measures to minimize water pollution and maximize water efficiency 
- What intensity of action(s) is/are being taken for water resource protection?

2. Flood defence and runoff prevention

- What is the condition of your flood defence or water runoff mitigation system?

3. Water audit and management plan

- Have you completed a water audit/management plan and if so are you acting on it?

4. Irrigation

- Do you irrigate crops?

- What \% of UAA is irrigated using mains or abstracted water?

- What application system do you use?

- Do you summer irrigate from mains/abstracted water or collect/store water over winter and extract when necessary?

- Is the cleanliness $/ \mathrm{pH} / \mathrm{salinity}$ of water used for irrigation monitored and at what frequency?

Fertilizer Management

1. Nutrient planning

- How do you determine the level of nutrient application for crops?

- How regularly do you monitor/record levels of major nutrients (eg: $\mathrm{P}, \mathrm{K}, \mathrm{Mg}, \mathrm{C}, \mathrm{S}$ ) in the soil?

- "How regularly do you monitor/record levels of major nutrients in crops (e.g., N, K, P, Mg, $\mathrm{Ca}, \mathrm{Na}, \mathrm{S})$ ?"

- To what extent are staff trained in the accurate/efficient application of nutrients to crops?

- Do you know the N, P, K content of organic manures/composts applied?

2. Manure Storage

- How do you predominantly store/manage manure on farm?

- How often do you completely empty and inspect manure storage facilities?

3. Manure application

- How frequently do you make manure applications to individual fields?

- At what time of year do you spread manures?

- How many hours after spreading do you incorporate solid manures?

4. Farm waste disposal

- What percentage of farm waste (e.g., plastics, metals, timber, etc.) is recycled?

- How do you dispose of unused/unwanted medicines?

- Does the farm have a written waste strategy (i.e., detailing waste avoidance strategies, waste disposal)?

Energy and Carbon

1. Energy saving options

- Do you monitor/record on-farm energy use?

- Have you completed an energy audit to explore efficiency options, and are you acting on it?

- Are tractors and other farm vehicles serviced regularly according to the manufacturer's maintenance schedule? 
2. Greenhouse gases

- Have you completed a greenhouse gas audit and are you acting on recommendations?

- Do you burn heather, grasses, rough grass, gorse, bracken and Vaccinium species (such as blueberries)?

- How regularly do you have on-farm fires for waste/residue disposal?

- Which burning method do you use for fires?

- Do you avoid burning plastics, oil and other toxic materials?

- Do you use peat-based growing media? (select N/A if horticultural crops are not grown)

3. Land use change

- Have you converted woodland or grassland to arable in the last 20 years? If so what $\%$ of your total woodland/grassland was converted?

- Have you converted arable land to permanent grassland or woodland in the last 20 years? If so, what $\%$ of your total arable area was converted?

- RenewablesDo you produce energy for on-farm use (not farmhouse) e.g., solar energy, woodchip for heating, ground-source heat?

- Do you export energy off-farm (e.g., farmhouse, neighbours, national grid) and if so, how much/how regularly?

- Have you considered your current use of non-renewable/intensive/short term materials (e.g., plastic, paper, cardboard packaging), and are you moving towards renewable/recycled/long lasting materials?

Food Security

1. Total productivity

- How would you describe your livestock productivity compared with similar types of farm?

2. Local food

- Approximately what percentage of your produce sold for human consumption (by weight) is sold to the following: local sales $(<25 \mathrm{~km})$ ? regional sales? national sales? international sales?

3. Breeds adapted for local conditions

- Do you use breeds adapted to local conditions?

4. Off-farm feed

- How much of your total feed (forage and concentrate) is bought in from off-farm?

5. Food quality and traceability

- Are animals correctly identified and is product traceability ensured?

- Are product quality controls carried out to ensure that required standards are met?

- What level of food quality certification do you have? Farm assured, Global GAP/Europe GAP, organic certification

Agricultural Systems Diversisty

Landless livestock production system (i.e., 100\% housed AND all feed produced off-farm)?

1. Rotational and varietal diversity

- How diverse is the crop rotation on your farm in terms of numbers of crop types? 
- How diverse is your temporary grassland in terms of number of species/varieties?

2. Marketing outlets

- Through how many outlets do you market your produce?

3. On farm processing

- Do process on farm products?

4. Livestock diversity (the following were calculated from the initial data collection sheet)

- How diverse is the livestock system on the farm with regard to numbers of species?

- How diverse is the livestock system on the farm with regard to numbers of breeds/crossbreeds: Sheep and goats? Other livestock? Total?

- Do you use access/make use of traditional gene pools in selection of livestock breeding stock?

\section{Social Capital}

1. Employment

- How many staff do you employ? (including yourself) Casual? Long term? family labour?

- Do you have written labour contracts with your employees that meet national labour standards?

- If you have any employees aged under 16, are you confident that their farm work is not affecting their education?

2. Skills and knowledge

- How many training days have staff (including the farmer) had per year in total-number of days per person: Casual? Long term?

3. Community engagement

- How many community events do you attend as a farm per year (this excludes events just for sales, like many farmers markets)?

- Do you use any of the means of communication listed below: information boards? farm walks? website? farm shop? farmers' markets? research/demonstrating projects? open days? farmhouse inn or bed and breakfast? other?

- Do you sell produce direct to customers on-farm?

- How many visitors come through the farm gate each year?

4. Public access

- Do you promote public access?

5. Human health issues

- How exposed are you or your workers to hazardous chemicals?

- Have you completed, up-to-date (within the last 12 months and including any more recent major changes) risk assessments for all individuals who work on the farm, paid and unpaid (completed by individuals)?

- How onerous (tough) is the workload on your farm?

- Do you share your workload with neighbouring farmers?

- Are you happy with the amount of holiday period you can take over a year? 
1. Key performance data

- Total revenue-SHEEP and GOATS excl. subsidy.

- Total revenue-OTHER ENTERPRISES (e.g., other livestock and crop sales) excl. subsidy.

- Total revenue-CAP support and other subsidies.

- Other revenue.

- Purchased concentrate and compound feed costs FOR SHEEP AND GOATS ONLY

- $\quad$ Purchased forage costs FOR SHEEP AND GOATS ONLY

- Veterinary/medicine costs FOR SHEEP AND GOATS ONLY: Vet fees Vaccination Antibiotics Anthelminitics Other Total vet/medicine costs

- How have your net assets (total assets less total liabilities) changed in the last year?

2. Farm resilience

- Have you been able to carry out the investment you would like? None, some, about half, most, all.

- How many sources of farm income do you have? (see list in row 152 below for examples).

- How often do you review the financial state of your business?

- How is your farm doing? Struggling, surviving, making a reasonable living, booming.

- Do you expect to still be in business next year?

- Do you expect your farm to still be farmed in the next decade?

- Do you have a sale agreement with your purchaser for the quantity of milk or lambs (or kids)

3. Flexibility

- How flexible are you in your choice of inputs and input suppliers?

- How flexible are you in the choice and the number of outputs and services?

4. Vision/strategy

- Do you have a recent (produced less than 5 years ago) business plan for your company?

- Do you carry out benchmarking activities to compare your performance to that of similar farms?

- Do you have a succession plan? (i.e., a plan for the person who is going to take over the farm)

5. Information searching/networking

- Do you use several information sources (e.g, farming press, consultants, research institutions, fellow farmers, training courses, customers) when making decisions regarding the management of the farm?

- Are you a member of more than one association (e.g., professional or sector organisations, marketing organisations or co-operatives, hobby clubs, ... )?

Animal Health Questions

1. Staff resources

- How often per day are livestock inspected for signs of illness/injury?

- Are your stockpeople trained?

- Number of annual labor units (ALU) looking after sheep and goats?

- One ALU is one full time employee working 2200 hours per year.

2. Animal health 
- Do you have a structured and documented approach for implementation of the following treatments: Vaccination? Antibiotic treatment? Internal parasite treatments/de-worming? External parasite treatment?

- Do you consider disease prevention and morphology in breed/breeding stock selection (this may include considering rare/traditional breeds suited to your area of the country)?

- What is your culling strategy?

- How would you describe the mortality rates on your farm?

- How would you describe the culling rates on your farm?

- What is the mortality rate of newborns on your farm?

- How soon after birth do lambs/kids receive colostrum?

- Please indicate the longevity of your breeding animals:

- How would you describe lameness incidence in your animals?

- What management methods do you use to reduce parasite burdens while minimizing the use of anthelmintics?

- How would you describe hair/fleece problems in your animals (including alopecia, ectoparasites, maggots, photosensitivity, abscesses, etc.)?

- How would you describe mastitis incidence and udder asymmetry in your herd/flock (n/a if you do not have dairy goats or sheep)?

- Please indicate the extent of feed related disorders (e.g., acidosis, hair/fleece pulling, ketosis, enterotoxemia)

- What is the age of female animals at first mating?

- What is the age of male animals at first mating?

- If using natural mating, how many males are used per 100 females?

- What is the conception rate in terms of \% of artificial insemination serves resulting in conception? (if using a ram or male goats select $\mathrm{n} / \mathrm{a}$ ).

- If using artificial insemination do you use estrus synchronization?

- Please define the sanitary status of your farm.

- How often does the vet visit your farm?

- How often do you use antibiotics?

- How does your flock perform in terms of milk somatic cell counts? (take note of average/range if possible for comparisons)

- How do your animals perform at the abattoir inspection?

3. Biosecurity

- Do you have a biosecurity plan in place?

- How do you deal with new livestock coming on to your farm?

\section{Animal Welfare}

1. Ability to perform natural behaviors

- How many months do the animals have access to pasture?

- Approximately how many hours per day do the animals graze in each season? Summer Autumn Winter Spring

- When not on pasture, do they have access to outdoor run?

- According to your system how do you judge your animals' ability to perform natural behavior?

- Feeding

- $\quad$ Resting 
- Social/comfort

- How frequently are abnormal behaviors observed in your flock?

2. Housing

- How would you describe the housing options available to your livestock? Below basic welfare standards, according to basic standards, higher than basic standards, much higher than basic standards?

- Please describe the status of your indoor stocking density

- Please describe the condition of your bedding material

- How stressed are the animals at milking as a result of the design of the dairy/milking parlor facility?

- Do you use appropriate animal handling facilities?

- What is the state of repair of your livestock housing?

- Is feed positioned to minimize the risk of contamination?

- Is water positioned to minimize the risk of contamination?

3. Feeding

- How much space is available to the animals when eating?

- What is the feeding strategy?

- Do you feed groups of animals according to physiological needs?

- How much of the feed is roughage?

- When is water available (refers to both grazing and housed periods)?

\section{Governance}

1. Ethics

- When making farm management decisions, do you take account of the effects they are having outside the farm boundary? For example, the environmental performance of your suppliers, the impact of your water use/management on others or the social impacts of your practices in terms of noise, pollution and community life?

2. Accountability

- Have you previously assessed the sustainability of the farm with a recognized sustainability assessment (SA) tool in the past?

3. Participation

- Do you work together (information sharing, co-ops, shared outlets ... ) with other stakeholders in the production chain-other farmers, advisors, suppliers, control/certifying bodies, retailers, government/policy people, NGOs, community groups.

4. Rule of law

- Are you aware of, and compliant with, all national laws and international agreements related to employment law (if applicable-applies if volunteers present) and farming? Include any accidental breaches

5. Holistic management

- In what ways have you changed your farming practices recently (last 3 years) in the light of new knowledge and research? How do you find out about it? 


\section{References}

1. World Commission on Environment and Development. Our Common Future; Oxford University Press: Oxford, UK, 1987.

2. Food and Agriculture Organization (FAO). SAFA Sustainability Assessment Of of Food And and Agriculture Systems Guidelines; FAO: Rome, Italy, 2014; ISBN 978-92-5-108485-4.

3. United Nations General Assembly (UNGA). Transforming Our World: The 2030 Agenda for Sustainable Development; UNGA: New York, NY, USA, 2015.

4. United Nations Department of Economic and Social Affairs Population Division. World Population Prospects 2019 Highlights; United Nations: New York, NY, USA, 2019.

5. United Nations. The Sustainable Development Goals Report; United Nations: New York, NY, USA, 2019.

6. Food and Agriculture Organization of the United Nations (FAO). Milk and Dairy Products in Human Nutrition; FAO: Rome, Italy, 2013; ISBN 978-92-5-107863-1.

7. Ragkos, A.; Theodoridis, A.; Arsenos, G. Alternative Approaches of Summer Milk Sales from Transhumant Sheep and Goat Farms: A Case Study from Northern Greece. Sustainability 2019, 11, 5642. [CrossRef]

8. Morales-Jerrett, E.; Mancilla-Leytón, J.M.; Delgado-Pertíñez, M.; Mena, Y. The Contribution of Traditional Meat Goat Farming Systems to Human Wellbeing and Its Importance for the Sustainability of This Livestock Subsector. Sustainability 2020, 12, 1181. [CrossRef]

9. Ronchi, B.; Nardone, A. Contribution of organic farming to increase sustainability of Mediterranean small ruminants livestock systems. Livest. Prod. Sci. 2003, 80, 17-31. [CrossRef]

10. Peacock, C.; Sherman, D.M. Sustainable goat production-Some global perspectives. Small Rumin. Res. 2010, 89, 70-80. [CrossRef]

11. Bernués, A.; Boutonnet, J.P.; Casasús, I.; Chentouf, M.; Gabiña, D.; Joy, M.; López-Francos, A.; MorandFehr, P.; Pacheco, F. Economic, social and environmental sustainability in sheep and goat production systems. Proceedings of the 7th International Seminar of the Sub-Network on Production Systems of the FAO-CIHEAM Inter-Regional Cooperative Research and Development Network on Sheep and Goats, Zaragoza, Spain, 10-12 November 2010. Options Méditerr. Sér. A Sémin. Méditerr. 2011, 100, 1-379.

12. Ripoll-Bosch, R.; Díez-Unquera, B.; Ruiz, R.; Villalba, D.; Molina, E.; Joy, M.; Olaizola, A.; Bernués, A. An integrated sustainability assessment of mediterranean sheep farms with different degrees of intensification. Agric. Syst. 2012, 105, 46-56. [CrossRef]

13. Bossis, N. Première analyse de la durabilitédes systèmes caprins. Chèvre 2004, 265, 33-36.

14. Nahed, J.; Castel, J.M.; Mena, Y.; Caravaca, F. Appraisal of the sustainability of dairy goat systems in Southern Spain according to their degree of intensification. Livest. Sci. 2006, 101, 10-23. [CrossRef]

15. Arsenos, G.; Baraldi, A.M.; Compagnoni, A.; DeBruyne, L.; Dragomir, C.; Gelasakis, T.; Braad Kudahl, A.; Marchand, F.; Nykänen, A.; Rufino, P.; et al. Rapid Sustainability Assessment of Organic and Low-Input Farming across Europe and Identification of Research Needs; Leach, K., Gerrard, C., Padel, S., Eds.; Organic Research Center: Newbury, UK, 2013. Available online: https://orgprints.org/22721/1/Deliverable\%20D\%201.1\% 20Final\%20New\%20Title\%2020\%20May.pdf (accessed on 11 April 2020).

16. Warhurst, P.A. Sustainability Indicators and Sustainability Performance Management. Mining, Minerals and Sustainable Development (MMSD); Warwick, UK, 2002. Available online: https://pubs.iied.org/pdfs/G01026.pdf (accessed on 11 April 2020).

17. Sala, S.; Ciuffo, B.; Nijkamp, P. A systemic framework for sustainability assessment. Ecol. Econ. 2015, 119, 314-325. [CrossRef]

18. Ness, B.; Urbel-Piirsalu, E.; Anderberg, S.; Olsson, L. Categorising tools for sustainability assessment. Ecol. Econ. 2007, 60, 498-508. [CrossRef]

19. Singh, R.K.; Murty, H.R.; Gupta, S.K.; Dikshit, A.K. An overview of sustainability assessment methodologies. Ecol. Indic. 2009, 9, 189-212. [CrossRef]

20. Marta-Costa, A.A.; Silva, E. Approaches for Sustainable Farming Systems Assessment. In Methods and Procedures for Building Sustainable Farming Systems; Marta-Costa, A.A., Silva, E., Eds.; Springer: London, UK, 2013; pp. 21-29.

21. Yañez-Ruiz, D.; Zaralis, K.; Belanche, A.; Smith, L.; Morin, E.; Mullender, S.; Martín-García, I. iSAGE Deliverable No: 1.2 Report on Identification of Indicators and Tools for Assessing the Sustainability of Sheep and Goat Farms; CSIC: Madrid, Spain, 2017. 
22. Zaralis, K.; Smith, L.; Belanche, A.; Morin, E.; Mullender, S.; Martín-García, I.; Yañez-Ruiz, D. Developing an assessment tool to evaluate the sustainability of sheep and goat farming systems in Europe. In Proceedings of the 8th International Conference on Information and Communication Technologies in Agriculture, Food \& Environment, Chania, Greece, 21-24 September 2017; pp. 633-641.

23. Gerrard, C.; Smith, L.; Padel, S.; Pearce, B.; Hitchings, R.; Measures, M.; Cooper, N. OCIS Public Goods Tool Development; Organic Research Center: Newbury, UK, 2011.

24. Ragkos, A.; Koutsou, S.; Manousidis, T. In search of strategies to face the economic crisis: Evidence from greek farms. South Eur. Soc. Polit. 2016, 21, 319-337. [CrossRef]

25. Theodoridis, R.A.; Ragkos, A.; Zaralis, K.; Mullender, S.; Rose, G.; Arsenos, G. iSAGE Deliverable No: 1.1 Report on New Farm Typologies for Sheep and Goat Systems within the EU for iSAGE; Aristotle University of Thessaloniki: Thessaloniki, Greece, 2016.

26. Eurostat Agricultural Holdings by Age of Holder. Available online: https://ec.europa.eu/eurostat/ databrowser/view/TAG00029/default/table (accessed on 2 February 2020).

27. Gelasakis, A.I.; Rose, G.; Giannakou, R.; Valergakis, G.E.; Theodoridis, A.; Fortomaris, P.; Arsenos, G. Typology and characteristics of dairy goat production systems in Greece. Livest. Sci. 2017, 197, $22-29$. [CrossRef]

28. Arsenos, G.; Gelasakis, A.; Pinopoulos, S.; Giannakou, R.; Amarantidis, I. Description and typology of dairy goat farms in Greece. In Proceedings of the 4th ISOFAR Scientific Conference, Istanbul, Turkey, 13-15 October 2014; pp. 13-15.

(C) 2020 by the authors. Licensee MDPI, Basel, Switzerland. This article is an open access article distributed under the terms and conditions of the Creative Commons Attribution (CC BY) license (http://creativecommons.org/licenses/by/4.0/). 